\title{
Comparative anatomical and histological features of the kidney in Harrier (Circus aueroginosus), Chicken (Gallus domesticus) and Mallard duck (Anas platyrhynchos)
}

\author{
Dhyaa, Ab.Abood; Ali, F. Reshag; Azhar, S. K. and Myson, A. Ahmed \\ Department of Anatomy,Histology and Embryology, College of Veterinary Medicine \\ University of Baghdad, Iraq. \\ E-mail: sabahali503@yahoo.com \\ Accepted on: 10/3/2014 \\ Summary
}

The aim of this study was to compare anatomical and histological of the kidney in three type of birds. The study revealed that, in harrier species the cranial lobe of kidney was the largest with elongated shape. In mallard the cranial lobe was small round-oval, while middle and caudal lobe were lobulated and larger .In chicken the caudal lobe was the largest. Statistically, in harrier the mean length of cranial lobe $(20 \pm 0.1 \mathrm{~mm})$ and the width of the middle lobe $(5 \pm 0.5 \mathrm{~mm})$ were significantly higher than those of mallard $(10 \pm 0.3 \mathrm{~mm})(8.0 .2 \mathrm{~mm})$ and chicken $(15 \pm 0.2 \mathrm{~mm})$ $(4 \pm 0.4 \mathrm{~mm})$ respectively. The mean weight of the kidney in harrier is $(5.8 \pm 0.20 \mathrm{~g})$ this value significantly was higher than those of mallared $(8.9 \pm 0.11 \mathrm{~g})$ and chicken $(6.8 \pm 0.10 \mathrm{~g})$ in compare to the total body weight. Histologically, in harrier species the kidney had larger cortical region and the nephron types were numerous of mammalian type in medulla and few of reptilian type was presented in sub-capsular region. In mallard species the renal lobule was relatively divided into two equal cortical and medullary regions and the nephrons showed two types, numerous of mammalian and reptilian types presented in medulla and intermediate zone of kidney. In chickens the cortical region was the larger compared to medullary region which contained numerous mammalian types and few of reptilian type.

\section{Keywords: Kidney, Anatomy, Histology, Chicken, Harrier, Mallard duck.}

\section{Introduction}

The kidney of bird is flattened organs embedded in ventral surface of synsacrum bone and each incompletely divided into three lobes; cranial, middle and wider-largest caudal lobes (1). Avian kidney lobes are showing subdivion; into units called lobules. Each lobule has a cortex and medulla, (2-5). The nephron is the functional unit of kidney and greatly varies in its structure amongst different vertebrates; also the structure of nephrons shows variable degree of differences among species. In birds, kidneys have two kinds of nephrons a reptilian type. small sized, with no loops of Henle, and a mammalian type large size with long or intermediate length loops (68). Many studies have been published on the histology of the mammalian kidney, but comparatively were few about avian kidneys. The aim of study was to investigate the anatomical and histological differences of the kidney in three species of bird, Harrier (as pattern of Kessler and wild birds), Mallared duck (as a pattern of marine birds) and the chicken (as a pattern of domestic birds).

\section{Materials and Methods}

Three avian species were chosen including Marsh harrier (Circus aueroginosus), Mallard duck (Anas platyrhynchos), and Broiler Chickens (Gallus domesticus).Five healthy birds of each species were used in this study. All birds of this study were collected from local markets. Before animals scarifying, body weight of each bird was calculated. The birds were euthanized by intravenous injection of an overdose of Phenobarbital-sodium through the wing vein. Kidneys samples were removed out of synsacral fossa.The total weight of each kidney were recorded while the length and width of each kidney lobe were measured immediately after obtaining the kidneys from the cadavers. The percentage of kidney weight to the total body weight was calculated.The area of cortex and medulla was estimated using an oculometer. The weight of the 
kidneys was calculated according to the formula used by (9) as follows:

$$
\text { Index of kidney weight }=\frac{\text { weight of kidney }}{\text { body eight }}
$$

The kidneys samples were fixed in $10 \%$ formalin then the routine histological technique was done, all the tissues sections were stained with Hematoxylin and Eosin (10).

\section{Results and Discussion}

The present study showed that, the kidneys of all studied birds were flattened organs which extended from the ventral aspect of the lungs to the end of the synsacrum, occupied the synsacral fossa and their color was brown in harrier and chicken while in Mallared the color was grayish. Each kidney consisted of three lobes; cranial, middle and caudal. The shapes of kidney lobes showed some difference, in harrier the cranial lobe of kidney was the largest,and elongated shape compared to those elongated middle and triangular-shape caudal lobe, (Figs. 1 and2). In mallard, the kidneys cranial lobe was small round-oval in shape. The middle lobe was elongated and the caudal lobe was the largest and most elongated, (Fig. 3). In chicken the cranial ,middie and caudal lobes showe relatively large (Fig. 4 and5).

The statistical measurements of kidneys lobes and their length, width and total lengths in all species were shown in (Table, 1)

The total weights of kidneys (left and right) and their percentage to total body weight showed differences, (Table, 2). The kidneys of all studied birds were divided into units called lobules. Each lobule has a cortex (outer area), and medulla or medullary cone (inner area). The cortex composed of large and small renal corpuscles (mammalian type) or (reptilian type), each renal corpuscle consisted of Bowman's capsule and glomerulus.

The proximal and distal convoluted tubules and collecting tubules were lined by simple cuboidal epithelium. Medulla of kidney was composed of thin and thick segment of Henle loop and collecting ducts, these structures were lined by simple cuboidal epithelium. The collecting ducts continued to form the papillary ducts, which lined by simple columnar epithelium. In addition to number of capillaries this called vasa recta.

In harrier, the renal nephrons (Glomeruli) were located in the medulla and intermediate zone (between cortex and medulla) involved numerous of mammalian type (large and intermediate size), while the reptilian type (small size) was few and most of this type present in sub capsular region of each lobule, (Fig. 6). The volume of cortex ranged from 60$70 \%$ and the medulla was $30-40 \%$. In mallard, the nephrons showed two types, numerous of mammalian and reptilian types which located in medulla and intermediate zone, (Fig. 7).

The volume of cortex ranged from 50-52\% and of medulla was $48-50 \%$. In chickens the nephrons showed three types, numerous mammalian types of two sizes (large and intermediate types), and few of reptilian type (small size) located in medulla (Fig. 8). The volume of cortex was $80-85 \%$ and medulla was $15-20 \%$.

Table, 1: illustrated the measurements of kidneys' lobes and their total lengths $(n=5$ in each species) $(\mathrm{N}=15)$.

\begin{tabular}{|c|c|c|c|c|c|c|c|}
\hline \multirow[t]{2}{*}{ Species } & \multicolumn{2}{|c|}{ Cranial lobe } & \multicolumn{2}{|c|}{ Middle lobe } & \multicolumn{2}{|c|}{ Caudal lobe } & \multirow{2}{*}{$\begin{array}{l}\text { Total } \\
\text { length } \\
\text { / mm }\end{array}$} \\
\hline & $\begin{array}{l}\text { Length } \\
\text { /mm }\end{array}$ & $\begin{array}{l}\text { Width } \\
\text { /mm }\end{array}$ & $\begin{array}{l}\text { Length } \\
\text { /mm }\end{array}$ & $\begin{array}{l}\text { Width } \\
\text { /mm }\end{array}$ & $\begin{array}{l}\text { Length } \\
\text { /mm }\end{array}$ & $\begin{array}{l}\text { Width } \\
\text { /mm }\end{array}$ & \\
\hline Circus aueroginosus & $20 \pm 0.1$ & $9 \pm 0.2$ & $7 \pm 0.1$ & $5 \pm 0.5$ & $9 \pm 0.2$ & $4 \pm 0.2$ & $36 \pm 2$ \\
\hline Anas platyrhynchos & $10 \pm 0.3$ & $6 \pm 0.1$ & $20 \pm 0.1$ & $8 \pm 0.2$ & $30 \pm 0.2$ & $10 \pm 0.1$ & $60 \pm 1$ \\
\hline Gallus domesticus & $15 \pm 0.2$ & $11 \pm 0.1$ & $9 \pm 0.3$ & $4 \pm 0.4$ & $28 \pm 0.2$ & $9 \pm 0.2$ & $53 \pm 2$ \\
\hline
\end{tabular}




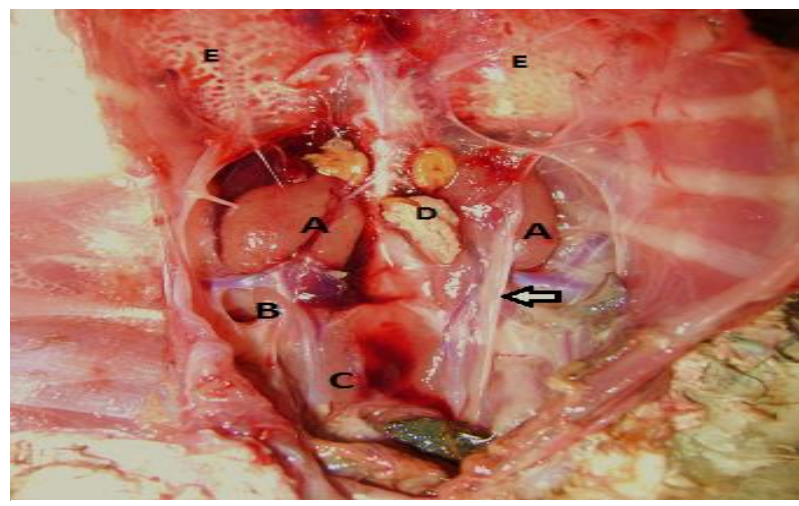

Figure, 1: Anatomical specimen of Harrier shows: (A) kidneys cranial lobe, (B) Kidneys middle lobe, (C) Kidneys caudal lobe, (D) Left ovary, (E) Lungs.

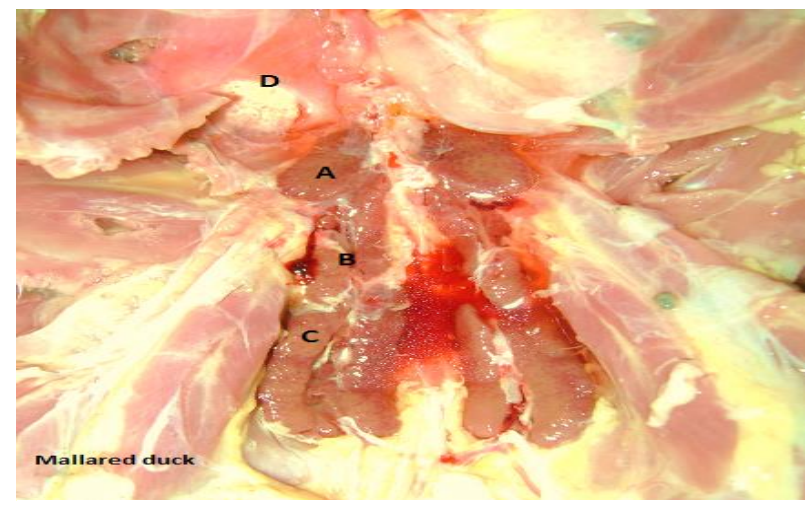

Figure, 3: Anatomical specimen of Mallard duck shows (A) kidneys cranial lobe, (B) Kidneys middle lobe, (C) Kidneys caudal lobe, (D) Lung

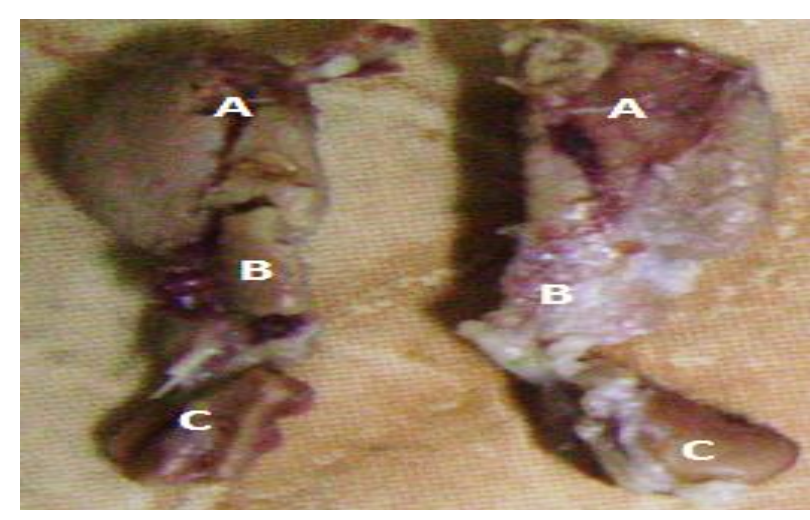

Figure, 2: Left and right kidneys after removal from cadavers shows: (A) Cranial lobe, (B) Midl lobe, (C) Caudal lobe, (Arrow shows oviduct).

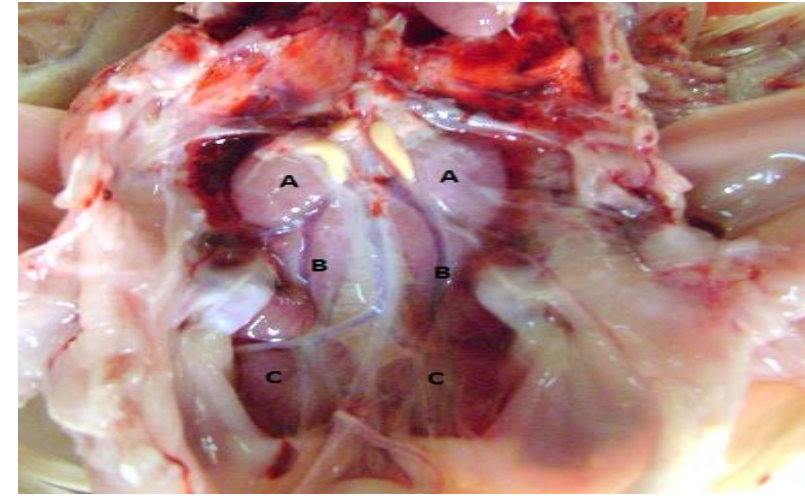

Figure, 4: anatomical specimen of chicken shows: ( A) Kidneys cranial lobe, (B) Kidneys middle lobe, (C) Kidneys caudal lobe.

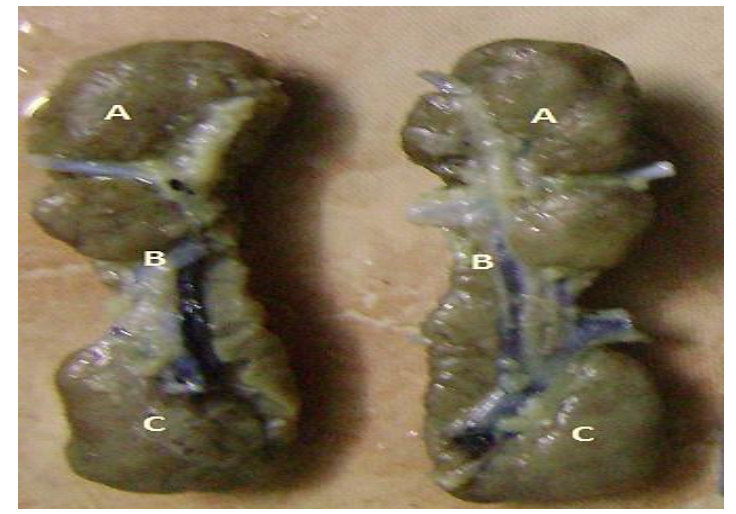

Figure, 5: left and right kidneys after removal from cadavers' shows :(A) Cranial lobe, (B) Middle lob, (C) Caudal lobe.

Anatomically the present study showed that, the kidneys of studied birds were similar in general morphology, the left and right kidneys had three lobes (cranial, middle and caudal), and occupied the synsacral fossa,this result was mentioned by $(1,11,12,13$ and 14). The color of kidney in three species were variable, this result suggest that is may be due to amount of blood they contain this supported by (15). The present study indicated that the mean length of harrier-cranial lobe of kidney statistically was higher $(\mathrm{p}<0.01)$ than those of Mallard and chicken, this result compatible with report of (12) in coot birds kidneys which 
consisted of three lobes, a large cranial (its length $28 \pm 0.15 \mathrm{~mm}$ and its width $13 \pm 0.08$ $\mathrm{mm}$ ), a small caudal (length $13 \pm 0.07 \mathrm{~mm}$ and its width $4 \pm 0.08 \mathrm{~mm}$ ) and a middle lobe (its length $30 \pm 0.08 \mathrm{~mm}$ and its width $7.5 \pm 0.10 \mathrm{~mm}$ ), while the parameters of present study in chicken and mallard showed that the caudal lobe in these birds were significantly the higher $(\mathrm{p}<0.01)$ this agree with $(1)$ in pigeon and with (16) in chicken found that the kidney is divided into rounded cranial, more slender middle expanded and irregularly shaped caudal division. Also our study revealed that, the mean total length kidneys in mallared duck was significantly the higher $(p<0.01)$ than those in harrier and chicken, this result agree with the report of (17) whom mentioned that, the mean total length of the right kidney $(60.6 \pm 0.047 \mathrm{~mm})$ and left kidney $(60.6 \pm 0.081 \mathrm{~mm})$ in Rhode Island Red chicken. While (14) mentioned that, the total length of the kidney in birds was $7 \mathrm{~cm}$. The present result showed that mean width of kidneys lobes in chicken and mallard was in compatible with result of (14).

Table, 2: illustrated the total weights of kidneys (left and right) $(n=5$ in each species $)(N=15)$.

\begin{tabular}{|c|c|c|}
\hline Species & $\begin{array}{c}\text { Total kidney weight/g. } \\
\text { Mean } \pm \text { SD }\end{array}$ & Kidney index \\
\hline Circus aueroginosus & $\mathbf{5 . 8 \pm 0 . 2 0}$ & $\mathbf{0 . 6 3 2}$ \\
\hline Anas platyrhynchos & $\mathbf{8 . 9 \pm 0 . 1 1}$ & $\mathbf{0 . 4 4 5}$ \\
\hline Gallus domesticus & $\mathbf{6 . 8 \pm 0 . 1 0}$ & $\mathbf{0 . 2 8 5}$ \\
\hline
\end{tabular}

This present result revealed that, the size of that, the mean weight of the kidney and its kidney was significantly larger $(p<0.01)$ in mallared duck than those in harrier and chicken, this result agree with (18) in his study on passerine birds which reported that, the birds possessing active salt glands have relatively larger kidneys than birds lacking active salt glands. The present result showed percentage to the total body weight was significantly higher $(\mathrm{p}<0.01)$ in harrier than those in mallard and chicken, this result suggests that, this differences was associated with birds, size (interspecific variation), this supported by opinion of (17) while this result disagree with (14).
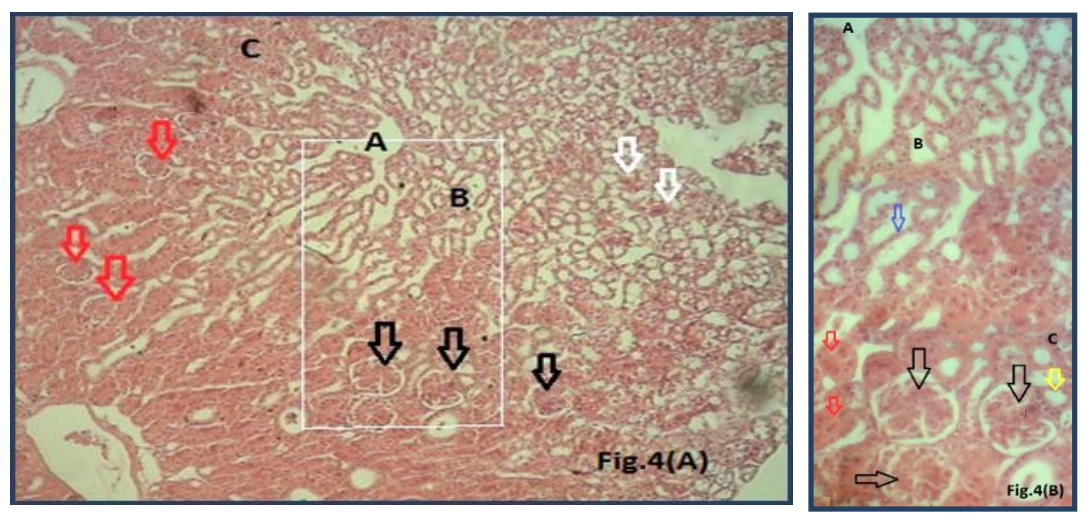

Figure, 6: Histological section of Harrier kidneys: (A) show: (A) Central vein. (B) Medulla. (C) Cortex. (Black arrows show mammalian Glomerulus-Red arrows show intermediate Glomerulus -White arrows show reptilian Glomerulus) H\&E stain 100x. (B) is magnifying of white box in left figure shows;( Red arrows show proximal convoluted tubules- yellow arrow shows distal convoluted tubule- blue arrow shows collecting tubule $\mathrm{H \& E} 400 x$. 


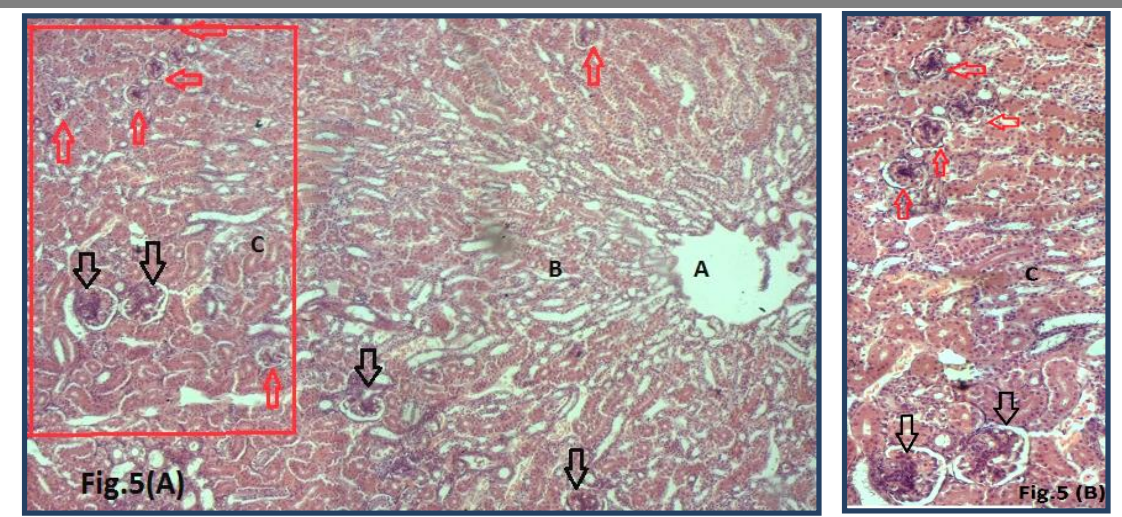

Figure,7: Histological section of mallard kidneys: (A) show: (A) Central vein. (B) Medulla. (C) Cortex. (Black arrows how mammalian glomeruli-Red arrows show reptilian type H\&E stain 100x. (B) is magnifying of red box in left figure $400 \mathrm{x}$.
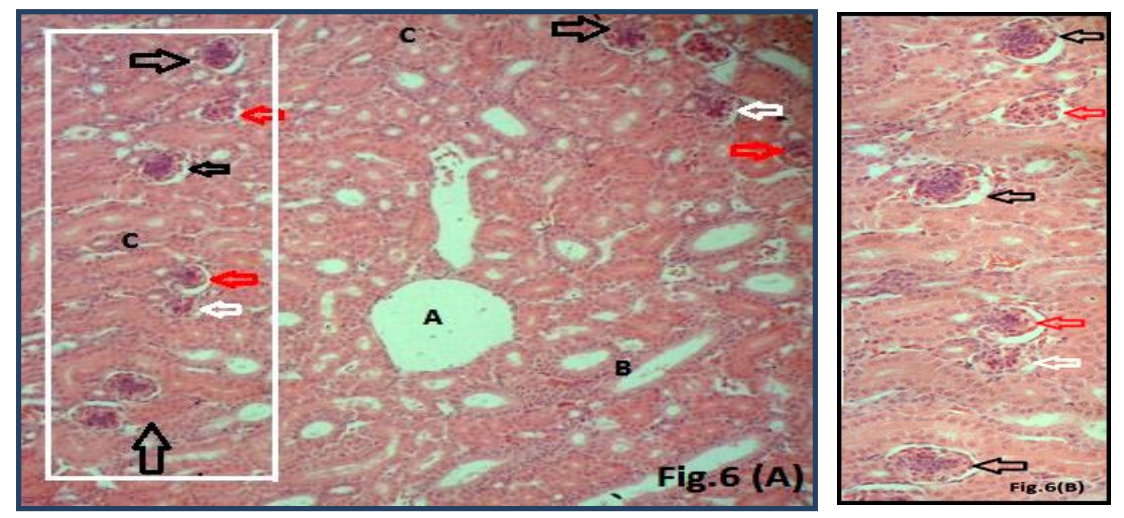

Figure, 8: Histological section of Chicken kidneys: (A) show: (A) Central vein. (B) Medulla. (C) Cortex. (Black arrows show mammalian Glomerulus - Red arrows show intermediate Glomerulus - White arrows show reptilian Glomerulus) H\&E stain100x. (B) is magnifying of white box in left figure- 400x.

Histologically, the study indicated that, there were three types of nephrons in the kidneys of chickens; this result was similar to result of $(13,15$ and 18$)$ and disagree with (1) in pigeon. Also in harrier there were three types of nephrons had been seen, this result suggest that, more numerous of mammalian and intermediate types of nephrons (looped nephrons) in these species are associated with food habits of these birds (watered on fresh water) this suggest that, these nephrons play an important role conserving body water, this supported by opinion of (19). While our study revealed that, in mallard duck there were numerous of both mammalian and reptilian types of nephrons, this suggests that, this type of birds which watered on sea water required more of reptilian type of nephrons which responsible for limited of urine concentration in order to expelled more of $\mathrm{NaCl}$ and assists supra orbital salt glands in their function (20). The distribution of these nephrons in kidneys of studied birds were different, the mammalian and intermediate types of nephrons were more numerous types in both chicken and harrier and both types of nephrons were located in medulla, while reptilian type was less numerous mostly located in sub capsular region of renal lobule, this result agrees with result of (12) in coot bird, while it disagrees with (7 and 15) who reported that, the reptilian type (with no loops of Henle) are located in the cortex, and a mammalian type (with long or intermediate length loops) are located in the medulla, also they reported that, in birds, only a small percentage of nephrons (15-25\%) contain a loop of Henle (looped nephrons).

In terms of volume the avian kidney consists of cortex which involves about 71$81 \%$, and small medulla which range $5-15 \%$ (21), the present study showed that, in chicken the volume of cortex ranged from $75-82 \%$ and medulla ranged from $10-15 \%$, this agree with 
result of (21), while in harrier the kidney lobules consist of about $60-70 \%$ cortex and $28-38 \%$ the medulla, in mallared the kidney lobules consist 50-55\% cortex and medulla was $38-42 \%$, this suggest that these variations are may be due to inter specific differences. According to findings of present study, it could be concluded that the gross anatomical parameters of the kidney were higher in harrier than chicken and mallard, whereas the histological parameter of the kidney were higher in chicken than others.

\section{References}

1. Al-Ajeely, R.A. and Fadhil, S. M. (2012). Morphohistological study on the development of kidney and ureter in hatching and adulthood racing pigeon (columba livia domestica). I.J.S.N., 3(3):665-677.

2. Bohle, M.A. and Christensen, J.A. (1985).

Structure of the avian kidney. Anat.

Record., 212: 33-40.

3. Johnson, O.W and Skodhauge, E, E. (1975). Structure-punctual correlations in the kidneys and an observation of colon and cloacal morphology in estuarine birds.J.Anat., 120:495-505.

4. Richardson, K. C; Wooller, R. D. and Castti, G. (1991). The relative size and a symmetry of kidneys in passerine birds from Asturalia and North America J.Anat., 175:181-185.

5. Casotti, G.; Lindberg, K. K. and Braun, E. J. (2000). Functional morphology of the avian medullar cone. Am. J. Physiol. Regul. Integr. Comp. Physiol., 279: 1722-1730.

6. Braun, E. J. (1999). Integration of organ systems in avian osmoregulation. J. Exp. Zoolo, 283:702-707.

7. McWhorter, T. J.; Martínez Del Rio, B. P. and Roxburgh, L. (2004). Renal function in Palestine Sunbirds: Elimination of excess water does not constrain energy intake. J. Exp. Biol., 207: 3391-3398.

8. Reece, W.O. (2004). Dukes' Physiology of Domestic Animals. $12^{\text {th }} \mathrm{Ed}$. Cornell University Press, Ithaca, PP: 107-113.

9. Federova, N. N. (1987). Growth and development of the reproductive system in White Leghorn in different lighting system,
Sbor. Nanch. Trud. Moskovaskaya Veterinaaya Akademiya. 128:37-40.

10. Luna, G. (1968). "Manual of histological staining methods of the armed forced institute of pathology". $3^{\text {rd }}$ Ed. McGraw Hill book Co. New York. , Pp: 71- 98.

11. Nabipour, A.; Alishahi, E. and Asadian, M. (2009). Some histological and physiological features of avian kidney. J. Appl. Anim. Res., 36:195-198.

12. Batah, A. L. (2012). Morphological and histological study for the kidneys of coot birds (Fulica atra). Bas. J. Vet. Res., 11:128-136.

13. Hodges, M. R. (1974). The histology of the fowl. In the urinary system. Academic press, London, New york, San Francisco, pp: 489-524.

14. Getty, R. (1975). "The anatomy of the domestic animals". Vol.2, Ithaca, New York, Pp: 1919-1925.

15. Mclelland, J. (1990). "A color atlas of avian anatomy"1 st Ed. Wolfe Publishing Ltd. London, pp: 75-81.

16. King, A.S. (1975). Aves urogenital system. The anatomy of domestic animals. In "Sisson and Grossman's: The Aves". 5 th Ed. R. Getty edit. Saunders, Philadelphia, London, pp: 1919-1926.

17. Islam, K. N.; Khan, M.Z.; Siddiqui, M.S.; Islam, M. R.; Lucky, N.S.; Lucky, M.K. and Adhikary, G.N. (2004).The anatomical studies of the kidneys of Rhode Island Red and White Leghorn chicken during their postnatal stages of growth and development. International J. of Poultry Sci., 3(5): 369-372.

18. Hodges, M.R. (1970). Relative kidney size in non-passerine birds with functional salt glands. The Condor, 72:(2):164-168

19. Siller, L. (1981). Renal pathology of the fowl- A review. Avian Pathol.,10: 187-262.

20. Nishimura, H. and Fan, Z. (2003). Regulation of water movement across vertebrate renal tubules. Comp. Biochem. Physiol. Part A, 136: 479-498.

21. Johnson, O.W. (1972). Relative thickness of the renal medulla in birds. J. of Morphol., 142:272-284. 


\section{الصفات التثريحية والنسجية للكلية في المرزة ( Circus aueroginosus ) و الاجاج Gallus (Anas platyrhynchos ) والثضيري (domesticus

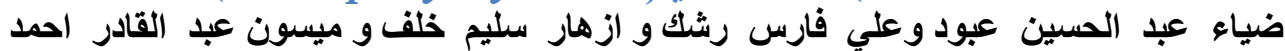 فرع التشريح و الانسجة و الاجنة ،كلية الطب البيطري ، وارئ جامعة بغداد، العر اق عاق}

\section{الخدلاصة}

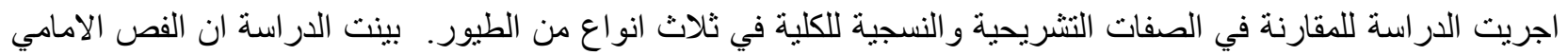

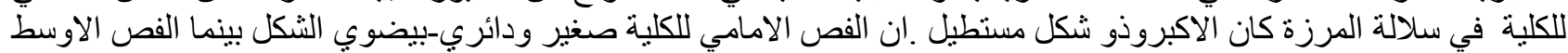

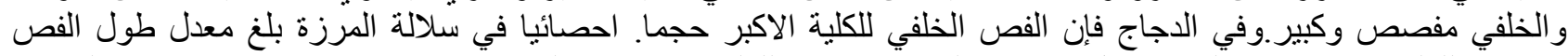

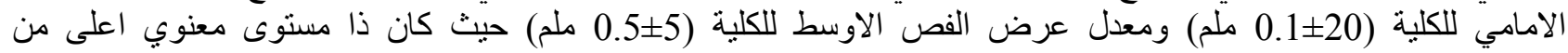

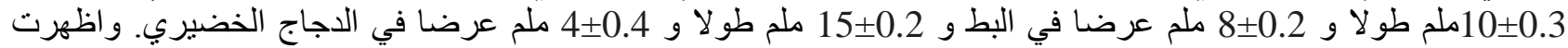

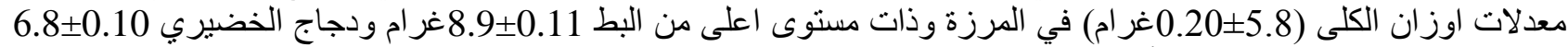

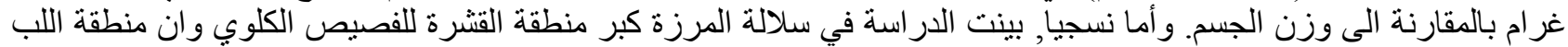

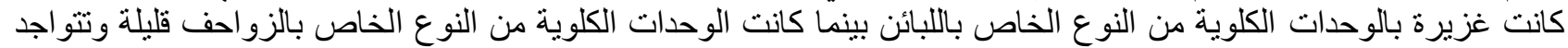

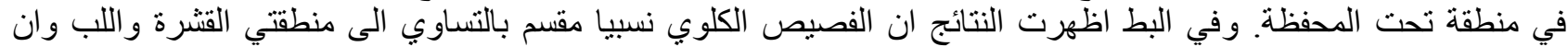

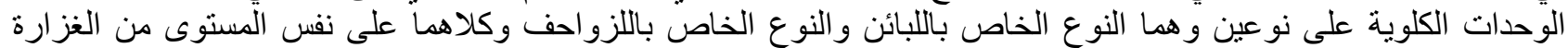

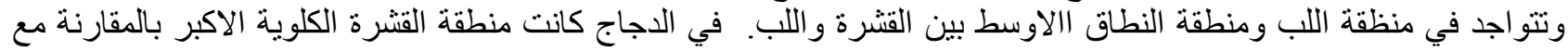

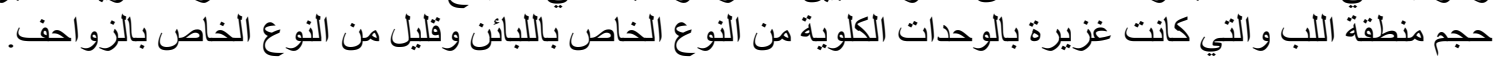

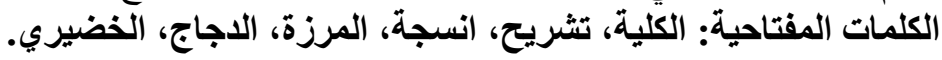

